\title{
TRABALHO ANÁLOGO A ESCRAVO
}

analogous to slave work

\author{
Gilca Garcia de Oliveira ${ }^{1}$ \\ Guiomar Inez Germani² \\ José Levi Furtado Sampaio ${ }^{3}$
}

\section{aaAaa}

\begin{abstract}
Resumo
A escravidão, legalmente garantida pelo Estado como forma de produzir riquezas, já não se faz presente no solo brasileiro como no momento da colonização. Mas atualmente, em momento de aceleração do tempo - o trabalho virtual e de conexões em rede - ainda se encontram, distribuídos em diversas partes do território brasileiro, trabalhadores sujeitos à condição análoga à escrava. Considera-se "trabalho escravo contemporâneo" ou "trabalho análogo a escravo", toda a condição de trabalho, mesmo que provisória, que apresente a coação física ou moral; privação da liberdade; que seja realizado em condições degradantes e sem garantia de direitos. Portanto, este artigo expõe para os diversos públicos interessados um levantamento dos estudos efetivados sobre as bases jurídicas que tratam das condições de trabalho no país e complementa com os processos definidores das espacialidades desta sujeição.
\end{abstract}

Palavras-chave: Trabalho decente, Trabalho escravo, Direitos humanos.

\begin{abstract}
Slavery legally guaranteed by the State as a means of producing wealth, is no longer present in Brazil as at the time of colonization. But today, in a moment of quickening of time - the virtual work as well as network connections - that is still spread in various parts of Brazil, were labor conditions are analogous to slavery. It is considered "contemporary slavery" or "work analogous to slavery" any labor condition, even if temporary, when presenting physical or moral coercion; deprivation of liberty; which is held in appalling conditions and without warranty of rights. Therefore, the article exposes to the various communities interested in a review of studies accomplished on the legal bases dealing with labor conditions in the country, and complements with the processes of defining spatialities of this subjection.
\end{abstract}

Key words:Decent Work, Forced Labor, Human Rights.

\begin{abstract}
Resumen
La esclavitud legalmente garantizada por el Estado como un medio de producción de riqueza, ya no está presente en Brasil como en el momento de la colonización. Pero ahora, en un momento de aceleración de tiempo - del despacho virtual y de las conexiones de red - se encuentran en varias partes del Brasil trabajadores sometidos a condiciones análogas a la esclavitud. Se considera "trabajo esclavo contemporáneo" o "mano de obra análoga a la esclavitud", todas las condiciones de trabajo, aunque sea temporal, a someterse a la coacción física o moral, la privación de la libertad, que se realiza en condiciones deplorables y sin derechos de garantía. Desde 2003 hasta 2011, fueron rescatados 39,180 trabajadores por el Grupo Especial de Fiscalização Móvel (GEFM), estas condiciones de trabajo en Brasil, siendo en su mayoría en los estados de Pará, Maranhão y Tocantins. Por lo tanto, este artículo presenta un examen de los estudios sobre los fundamentos jurídicos que se ocupan de las condiciones de trabajo en el País y complementa la espacialidad de estos los procesos.
\end{abstract}

Palabras clave: trabajo decente, trabajo esclavo, derechos humanos.

(1) Prof ${ }^{a}$. Dr ${ }^{\mathrm{a}}$. do Mestrado em Economia e Programa de Pós-Graduação em Geografia da Universidade Federal da Bahia - Rua Rio de São Pedro no. 43, apto 501, CEP: 40150-350, Salvador (BA), Brasil. Tel./Fax.: (+55 71) 3283 7553/3283 7542 - ggo@ ufba.br

(2) Bolsista Produrtividade do CNPq, Prof ${ }^{a}$. Dra . do Programa de Pós-Graduação em Geografia da Universidade Federal da Bahia - Rua Almirante Barroso no. 213, apto 403, CEP: 41950-350, Salvador (BA), Brasil, Tel./Fax.: (+55 71 ) 32838572 / 32838526 - guiomar@ufba.br

(3) Prof. Dr. do Programa de Pós-Graduação em Geografia da Universidade Federal do Ceará - Rua 69, casa 4, Residencial Henrique Jorge, Bairro Antônio Bezerra, 60510-733, Fortaleza (CE), Brasil - joselevi@uol.com.br

\section{aaCaa}

Revista da ANPEGE, v. 8, n. 9, p. 93-106, jan./jul. 2012.

ISSN 1679-768 X @ 2003, Associação Nacional de Pesquisa e Pós-Graduação em Geografia. Todos os direitos reservados. 


\section{INTRODUÇÃO}

A história da colonização do Brasil, conhecida por todos, tem notória característica de ocupação do território com vistas à exploração de suas terras para a produção destinada à exportação. Neste sentido, este processo foi explorador, expropriador e dilapidador dos recursos naturais, do trabalho e da cultura local. O trabalho escravo, primeiro do indígena e posteriormente do africano, era amplamente aceito como base para a produção de riqueza e fundamental para o sucesso do empreendimento comercial da Coroa Portuguesa.

A Independência do Brasil, em 1822, foi resultado de negociação entre a elite nacional, a Coroa portuguesa e a Inglaterra, mantendo a maioria da população excluída dos direitos civis e políticos e sem identidade nacional consolidada. O novo regime continuou dando amparo legal ao trabalho. De certa forma, a abolição da escravidão, em 1888, também foi resultado de negociações quando interessava mais ao capital esta forma de relação pouco produtiva. O Brasil foi o último país ocidental a declarar a abolição da escravatura e esta apresentou sentido maior de razão nacional do que de direitos individuais. Portanto, não havia políticas de inclusão desses trabalhadores "libertos" na sociedade brasileira, em termos, principalmente de educação, saúde, acesso e posse da terra e trabalho.

O trabalho não era regulado na cidade e muito menos no campo. Só bem mais tarde, em 1943, a luta dos trabalhadores urbanos se firmou através da Consolidação das Leis do Trabalho (CLT) e, apesar de não ter sido construída por meio de efetiva participação dos trabalhadores, foi um avanço alcançado pela categoria. Enquanto que a regulamentação do trabalho no campo se deu somente, 20 anos depois, em 1963, com o Estatuto do Trabalhador Rural (ETR). Isto significa que o País passa a dispor de um estatuto jurídico que regula as relações de trabalho, estabelece as condições em que esta relação deve se realizar e os direitos dos trabalhadores tanto no campo como na cidade.

Porém, atualmente, em um mundo onde o trabalho não tem fronteiras e as relações trabalhistas virtuais se ampliam em ambientes modernos com vistas a garantir o bem-estar social do trabalhador e a produtividade, se convive com situações em que o trabalho análogo ao de escravo ainda se mantém. São situações em que o empregado muitas vezes desconhece quem é seu empregador, está sujeito a trabalho duro, em condições degradantes, viabilizado por um intermediário denominado de "gato".

São frequentes as notícias de situações em que tem havido resgates de trabalhadores em condições análogas à de escravos, tanto no campo quanto na cidade. Mas é no campo que esse cenário se expressa e os excessos são mais profundos. A escravidão por dívida, o cerceamento da liberdade de deslocamento, a coerção por armas, se apresenta mais agressivamente nas unidades rurais, principalmente pelo isolamento e menor conhecimento dos direitos dos trabalhadores ali resgatados.

As ações contra o trabalho análogo ao de escravo vêm se ampliando com a presença do Grupo Especial de Fiscalização Móvel (GEFM) nos Estados. Mas em muito precisa ampliar suas ações para atender às denúncias que recebem e muito mais para atuar efetivamente na fiscalização, isto é, se adiantando às denúncias. De acordo com Oliveira et al. (2010), a fiscalização precisa conseguir quebrar os principais elos destes grilhões, com maior rigor nas punições para que o empregador não incorra mais nesse crime e que, ao mesmo tempo, se aumente as oportunidades de trabalho cuja possibilidade de escolha perpasse pela garantia de dignidade no processo de reprodução social do trabalhador.

O Brasil enquanto signatário do Pacto Internacional dos Direitos Econômicos, Sociais e Culturais (PIDESC), da Organização das Nações Unidas (ONU), se compromete a garantir, dentre outras questões, condições dignas de trabalho ao cidadão brasileiro. Em 2014, o Brasil apresentará seu terceiro relatório sobre as condições dos direitos humanos no País. Portanto, este momento se apresenta oportuno para a discussão da realidade do trabalho análogo ao de escravo no Brasil e ao mesmo tempo discutir com a sociedade e suas organizações, os direitos humanos e o trabalho decente, cuja Agenda Hemisférica o Brasil é signatário. São algumas destas questões e da realidade desta temática que se pretende tratar neste artigo. 
Para esta discussão, são trazidos elementos referentes aos direitos humanos e suas relações com o trabalho decente contrapondo-se ao trabalho análogo ao de escravo. Busca-se apoio na base moral e legal que dá sustentação para enquadrar esta relação como crime. Finalizando com as denúncias e os registros que confirmam a existência do trabalho escravo contemporâneo no Brasil, assim como as ações realizadas pelo Estado, alinhavadas nas estruturas de poder, com o intuito de alertar e esclarecer este debate necessário.

\section{DIREITOS HUMANOS E TRABALHO DECENTE: ELEMENTOS DE CONTRAPONTO AO TRABALHO ANÁLOGO A ESCRAVO}

Aparentemente, a diferença entre o enquadramento de trabalho escravo e condições análogas ao trabalho escravo é muito tênue ou quase nenhuma. Os limites deste enquadramento são dados pela história, isto é, quando este tipo de relação era aceito pela sociedade caberia tal denominação, à medida que cada país promulga um estatuto jurídico que bane e proíbe esta relação, ela passa a não ser mais admitida social e legalmente. A diferença, portanto não é somente conceitual, mas de enquadramento jurídico para poder ser caracterizada tal situação nos dias atuais.

O Quadro 1 apresenta um quadro comparativo quanto às características de trabalho escravo historicamente reconhecido e de trabalho escravo contemporâneo.

Quadro 1 - Comparação: escravidão antiga e a nova escravidão

\begin{tabular}{|l|l|l|}
\hline \multicolumn{1}{|c|}{ BRASIL } & \multicolumn{1}{|c|}{ Antiga escravidão } & \multicolumn{1}{|c|}{ Nova escravidão } \\
\hline Propriedade legal & Permitida & Proibida \\
\hline Custo de recrutamento & $\begin{array}{l}\text { Alto. A riqueza de uma pessoa podia ser } \\
\text { medida pela quantidade de escravos }\end{array}$ & $\begin{array}{l}\text { Muito baixo. Não há compra e, muitas vezes, } \\
\text { gasta-se apenas com o transporte. }\end{array}$ \\
\hline de mão de obra & $\begin{array}{l}\text { Baixos. Havia altos custos com a manutenção } \\
\text { dos escravos }\end{array}$ & $\begin{array}{l}\text { Altos. Se alguém fica doente ou velho pode ser } \\
\text { mandado embora, sem nenhum direito. }\end{array}$ \\
\hline Mão de obra & $\begin{array}{l}\text { Escassa. Dependia de tráfico negreiro, prisão } \\
\text { de índios ou dos novos escravos nascidos nas } \\
\text { fazendas }\end{array}$ & $\begin{array}{l}\text { Descartável, dado o grande contingente de } \\
\text { trabalhadores desempregados. }\end{array}$ \\
\hline Relacionamento & $\begin{array}{l}\text { Longo período. O dono cuidava dos escravos } \\
\text { pela vida inteira }\end{array}$ & $\begin{array}{l}\text { Curto período. Terminado o serviço, não é mais } \\
\text { necessário prover o sustento do empregado. }\end{array}$ \\
\hline Diferenças étnicas & Relevantes para a escravização & $\begin{array}{l}\text { Pouco relevantes. Qualquer pessoa pobre e } \\
\text { miserável pode se tornar escrava, independente } \\
\text { da etnia. }\end{array}$ \\
\hline Manutenção da ordem & $\begin{array}{l}\text { Ameaças, violência psicológica, coerção física, } \\
\text { punições exemplares até assassinatos }\end{array}$ & $\begin{array}{l}\text { Ameaças, violência psicológica, coerção física, } \\
\text { punições exemplares e até assassinatos. }\end{array}$ \\
\hline
\end{tabular}

Fonte: Reporter Brasil adaptado de Kevin Bales Disposable People: New Slavery in the Global Economy.

Observa-se que as condições postas se tornaram mais perversas na "nova" escravidão, uma vez que a ausência de oportunidades de trabalho leva os trabalhadores a se sujeitarem a condições degradantes de trabalho, muitas vezes com deslocamento para longe de seu núcleo familiar, configurando um movimento de migração. Enquanto que na "antiga", escravidão se dava de forma compulsória, atualmente, devido à condição de vulnerabilidade social, o trabalhador pode escolher - mas não há escolhas. Nesta relação de trabalho há a intermediação do "gato" que irá agir no aliciamento dos trabalhadores. Mas sua ação é mais que um simples elo entre trabalhador e empregador, porque o mesmo tem também o papel de coagir o trabalhador pelo uso de armas, impedindo o livre deslocamento, apreendendo documentos, ou seja, impondo a "ordem" local. Com a presença do "gato", a relação trabalhista se tornou mais impessoal, sendo que o trabalhador nem mesmo conhece o empregador, aquele que verdadeiramente o sujeita às condições degradantes de trabalho. Mas também se torna mais perversa, pois as condições de vulnerabilidade em que muitos se encontram levam a que se sujeitem e até agradeçam a intermediação do "gato". 
Apesar de a legislação trabalhista brasileira ser favorável à defesa da condição de dignidade do trabalhador, assim como o País ser signatário dos acordos internacionais que defendem esta condição, o que se verifica, na prática, é o não cumprimento das leis e o frequente rompimento dos acordos. Esta é uma situação inaceitável para qualquer país, ainda mais aos que buscam liderança de desenvolvimento na América Latina e ser exemplo de sucesso nas soluções de entraves econômicos, sociais e ambientais.

Os direitos garantidos pela sociedade são definidos como: civis, políticos e sociais. Direitos civis são aqueles fundamentais à vida, à liberdade, à propriedade, à igualdade perante a lei. Os direitos políticos se referem à participação do cidadão no governo da sociedade. Os direitos sociais se referem à garantia de equidade das oportunidades na sociedade. De acordo com Carvalho (2011, p.10) "se os direitos civis garantem a vida em sociedade, se os direitos políticos garantem a participação no governo da sociedade, os direitos sociais garantem a participação na riqueza coletiva".

A Declaração Universal dos Direitos Humanos (DUDH) aprovada, em 1948, em Assembleia Geral da Organização das Nações Unidas (ONU) tornou-se o paradigma dos direitos humanos, reconhecendo quanto aos direitos de igualdade, de universalidade, de indivisibilidade e de interdependência. De acordo com Miraglia (2011, p. 84) apesar desta Declaração “(...) ser tecnicamente uma recomendação, sua força vinculante é inegável”. Esta Declaração já no seu art. $1^{\circ}$ estabelece que "todos os homens nascem livres e iguais em dignidade e direitos. São dotados de razão e consciência e devem agir em relação uns aos outros com espírito de fraternidade."

Os artigos $4^{\circ}$ a $21^{\circ}$ tratam de diversos direitos civis e políticos, mas especificamente o Artigo $4^{\circ}$ diz que "Ninguém será mantido em escravidão ou servidão; a escravatura e o tráfico de escravos estão proibidos em todas as suas formas." O Artigo 5. diz que "Ninguém será submetido à tortura, nem a tratamento ou castigo cruel, desumano ou degradante." São estes artigos que tratam mais especificamente de combate ao trabalho escravo.

Os direitos foram agrupados em Pactos : Direitos Econômicos, Sociais e Culturais (PIDESC) e Direitos Civis e Políticos (PIDCP). Os Pactos Internacionais são assinados com o objetivo de efetivar os direitos defendidos. Somente em 1992 o Brasil assinou a ambos os Pactos.

É interessante observar que os Artigos $6 .^{\circ}$ a $15 .^{\circ}$ do PIDESC reconhecem o direito ao trabalho. O artigo $8^{\circ}$ do PIDCP diz que 1) "Ninguém será submetido à escravidão; a escravidão e o tráfico de escravos, sob todas as suas formas, são interditos. 2) Ninguém será mantido em servidão e 3) Ninguém será constrangido a realizar trabalho forçado ou obrigatório".

Apesar de se ter acordado que o país signatário deveria apresentar Relatório no ano de sua adesão, o primeiro Relatório apresentado pelo Brasil, quanto às condições de direitos humanos, foi apresentado 10 anos depois, em 2002. Este Relatório foi extremamente criticado pelas incoerências ali apresentadas. Em 2007, foi apresentado o segundo Relatório, melhor preparado, mas ainda assim, não foi bem avaliado. Em 2008, a sociedade civil apresenta um relatório alternativo buscando mostrar a verdadeira realidade nacional. Em 2014, será apresentado o novo relatório nacional e o debate quanto às condições trabalhistas devem ser ali incluídas.

A Organização Internacional do Trabalho (OIT) tratou da questão do trabalho análogo a escravo, especificamente em duas Convenções: a 29, de 1930; e a 105, de 1957. A primeira delas, a Convenção sobre Trabalho Forçado, trata da eliminação do trabalho forçado ou obrigatório em todas as suas formas. Enquanto que a segunda, a Convenção sobre Abolição do Trabalho Forçado, trata da proibição do uso de toda forma de trabalho forçado ou obrigatório como meio de coerção ou de educação política; castigo por expressão de opiniões políticas ou ideológicas; medida disciplinar no trabalho; punição por participação em greves; como medida de discriminação, mesmo que seja a pretexto de desenvolvimento econômico. O Brasil é signatário das duas Convenções supracitadas: a 29, de 1930, foi ratificada pelo Brasil em 25/04/1957; enquanto que a Convenção 105, de 1957, foi ratificada em 18/06/1965. 
O conceito de trabalho escravo empregado pela OIT considera que toda a forma de trabalho escravo é trabalho degradante, mas o recíproco nem sempre é verdadeiro. O que os diferencia é a liberdade, o trabalho escravo trata de cerceamento da liberdade dos trabalhadores em todas as dimensões.

O embate contra o trabalho escravo contemporâneo vincula-se à campanha mundial pelo trabalho decente. Entende-se Trabalho Decente como

[...] um trabalho produtivo e adequadamente remunerado, exercido em condições de liberdade, equidade e segurança, e que garanta uma vida digna a todas as pessoas que vivem do trabalho e a suas famílias. Permite satisfazer as necessidades pessoais e familiares de alimentação, educação, moradia, saúde e segurança (CEPAL/PNUD/OIT, 2008, p. 12).

Em 2006, o País aderiu, à agenda Hemisférica do Trabalho Decente com metas de reduzir em $20 \%$ a $35 \%$, no período de dez anos, o número de trabalhadores sob o regime de trabalho forçado.

Toma-se, também, como princípio o respeito aos direitos fundamentais explicitados na DUDH, que tratam da igualdade de direitos e de oportunidades em prol da dignidade humana. Portanto, o trabalho forçado ou análogo ao trabalho escravo se apresenta como uma negação completa aos elementos que caracterizam o trabalho decente. Em termos nacionais têm-se, principalmente, a Constituição Federal e o Código Penal como elementos de regulamentação da dignidade humana e do trabalho decente.

Miraglia (2011) relata que o Brasil, nas Constituições de 1946 e 1967, relacionavam a dignidade humana ao Direito do Trabalho, estabelecendo que seria garantido a todos o acesso ao trabalho que possibilitasse a existência digna. Em 1988, novo paradigma surge com a Constituição promulgada neste ano que consagra a dignidade humana como fundamento da República e princípio basilar da ordem social e econômica. Assim, no seu artigo $1^{\circ}$ (III e IV) elege como fundamentos da República Federativa do Brasil a "dignidade da pessoa humana" e os "valores sociais do trabalho".

Em temos legais, a Lei ${ }^{\circ} 10.803$, de 11 de dezembro de 2003, ao alterar o artigo 149, do Decreto-Lei ${ }^{\circ} 2.848$, de 7 de dezembro de 1940 - Código Penal Brasileiro -, dispõe sobre a questão, definindo o trabalho análogo a escravo e estabelecendo as penalidades:

Art. 149. Reduzir alguém a condição análoga à de escravo, quer submetendo-o a trabalhos forçados ou a jornada exaustiva, quer sujeitando-o a condições degradantes de trabalho, quer restringindo, por qualquer meio, sua locomoção em razão de dívida contraída com o empregador ou preposto:

Pena - reclusão, de dois a oito anos, e multa, além da pena correspondente à violência.

$\S 1^{\circ}$ Nas mesmas penas incorre quem:

I - cerceia o uso de qualquer meio de transporte por parte do trabalhador, com o fim de retê-lo no local de trabalho;

II - mantém vigilância ostensiva no local de trabalho ou se apodera de documentos ou objetos pessoais do trabalhador, com o fim de retê-lo no local de trabalho.

$\S 2^{\circ}$ A pena é aumentada de metade, se o crime é cometido:

I - contra criança ou adolescente;

II - por motivo de preconceito de raça, cor, etnia, religião ou origem. (BRASIL, 2003)

Mesmo com estas leis, normas e acordos assinados, muito ainda se têm encontrado quando se trata de trabalho análogo a escravo no Brasil. Daí surgirem os crimes e denúncias que serão abordados no item a seguir. 


\section{CÍRCULO VICIOSO: CONDIÇÕES DE VULNERABILIDADE, CRIMES, DENÚNCIAS, AÇÕES...}

Diversas denúncias são feitas no País, principalmente pela Comissão Pastoral da Terra (CPT), quanto à existência de trabalhadores submetidos a condições subumanas, análogas ao trabalho escravo, sendo pioneira a denúncia de Dom Pedro Casaldáglia, bispo de São Félix do Araguaia, Tocantins, já na década de 1970 .

Apesar destas denúncias, somente em 1995 o País reconhece a existência de tais práticas no território nacional, especialmente, pela repercussão internacional do caso Zé Pereira. Aos oito anos, Zé Pereira saiu com seu pai, de São Miguel do Araguaia (GO), para trabalhar em fazendas no Pará. Em 1989, Zé Pereira realizava trabalhos na Fazenda Espírito Santo, em Sapucaia, da qual foge sendo vítima de uma emboscada, promovida pelo "gato", onde é baleado junto com um amigo, Paraná, que também fugia das condições degradantes. Zé Pereira finge-se de morto e assim salva sua vida, mas Paraná morre na emboscada. Em Belém (PA) Zé Pereira presta queixa junto a Polícia Federal e, como não tem resposta, com o apoio das organizações não governamentais Americas Watch e do Centro pela Justiça e o Direito Internacional (Cejil) denuncia à Comissão Interamericana de Direitos Humanos, da OEA. No acordo proposto pelo Brasil, foi paga uma indenização de R \$52 mil a Zé Pereira, 14 anos depois de fugir da Fazenda.

Este caso é emblemático por ter tido repercussões internacionais e por ser a primeira indenização paga pelo Estado brasileiro a um trabalhador sujeito a condições análogas a escravo.

Como resultado das negociações, neste mesmo ano, foi criado, pela Portaria $\mathrm{n}^{0} 550$, de 14 de junho de 1995, o Grupo Especial de Fiscalização Móvel (GEFM) com o objetivo de combater a violação da legislação trabalhista e, especialmente, agir contra o trabalho análogo a escravo, resgatando trabalhadores sujeitos ao trabalho escravo e encaminhando as medidas legais cabíveis. São ratificadas nas operações de resgate do GEFM as condições subumanas destas relações de trabalho como: condições degradantes de alimentação, moradia, higiene, saúde, segurança; impedimento de livre mobilidade; servidão por dívida; retenção de documentação e coerção. O GEFM, ligado à Secretaria de Inspeção do Trabalho (SIT) do Ministério do Trabalho e Emprego (MTE), é formado por auditores fiscais do trabalho - que coordenam as operações de campo - policiais federais e procuradores do Ministério Público do Trabalho (MPT).

No Quadro 2, observa-se a situação geral das operações de fiscalização realizadas pelo GEFM, de 1996 a 2010, mostrando como vem se ampliando a ação do Grupo no Brasil. Neste período foram realizadas 1.082 operações, resgatados 39.180 trabalhadores, e efetuado o pagamento total de indenizações, que são as verbas salariais devidas ao empregado, cujo pagamento no curso da ação fiscal é decorrente do rompimento do contrato de trabalho, no valor de $\mathrm{R} \$ 62.247 .947,36$. No entanto, o que se observa é que mesmo com a ampliação do número de operações, ao longo dos anos, as mesmas não vêm sendo capazes de abolir este crime, uma vez que o número de trabalhadores resgatados não vem reduzindo de forma significativa. Há depoimentos de representantes do Ministério do Trabalho e Emprego (MTE) e do Ministério Público do Trabalho (MPT) de que as ações não têm conseguido alcançar todas as denúncias que estes órgãos vêm recebendo ao longo do ano, sendo necessária a formação de novos Grupos com maior disponibilização de recursos.

Houve também a inclusão dos trabalhadores resgatados no sistema de concessão de seguro-desemprego, por meio da Lei $\mathrm{n}^{0}$. 10.608, de 20 de dezembro de 2002, que garante ao trabalhador o direito de receber três parcelas do seguro-desemprego, no valor de um salário mínimo cada, cujos requisitos são: não ser aposentado pela Previdência Social, não ser beneficiário do seguro-desemprego comum, não ter encontrado outra ocupação (reemprego) ou por apresentar problemas na documentação (duplicidade de PIS entre outros) (BRASIL, 2002). O seguro-desemprego dificilmente compreenderá a totalidade dos resgatados, sendo que, no ano de $2008,81 \%$ dos trabalhadores libertos receberam o seguro-desemprego (BRASIL, 2009). De acordo com Brasil (2009, p. 7) "[...] compete aos auditores-fiscais do trabalho efetuar, por ocasião do resgate dos trabalhadores, a 
emissão dos requerimentos do benefício do seguro-desemprego especial, o qual é posteriormente sacado pelo próprio trabalhador na rede bancária”.

Quadro 2 - Situação geral das operações de fiscalização para erradicação do trabalho escravo, Brasil, 1996 a 2010*

\begin{tabular}{|c|c|c|c|c|c|c|}
\hline ANO & $\begin{array}{c}\text { N.ㅇ } \\
\text { Operações }\end{array}$ & $\begin{array}{l}\text { N.o de estab. } \\
\text { Inspecionados }\end{array}$ & $\begin{array}{l}\text { Trabalhadores } \\
\text { com contrato } \\
\text { formalizado na } \\
\text { ação fiscal }\end{array}$ & $\begin{array}{c}\text { Trabalhadores } \\
\text { Resgatados }\end{array}$ & $\begin{array}{l}\text { Pagamento } \\
\text { de Indenização }\end{array}$ & $\begin{array}{l}\text { Autos de } \\
\text { Infração } \\
\text { Lavrados }\end{array}$ \\
\hline 1995 & 11 & 77 & ND & 84 & ND & 906 \\
\hline 1996 & 26 & 219 & ND & 425 & ND & 1.751 \\
\hline 1997 & 20 & 95 & ND & 394 & ND & 796 \\
\hline 1998 & 17 & 47 & ND & 159 & ND & 282 \\
\hline 1999 & 19 & 56 & ND & 725 & ND & 411 \\
\hline 2000 & 25 & 88 & 1.130 & 516 & $472.849,69$ & 522 \\
\hline 2001 & 29 & 149 & 2.164 & 1.305 & $957.936,46$ & 796 \\
\hline 2002 & 30 & 85 & 2.805 & 2.285 & $2.084 .406,41$ & 621 \\
\hline 2003 & 67 & 188 & 6.137 & 5.223 & $6.085 .918,49$ & 1.433 \\
\hline 2004 & 72 & 276 & 3.643 & 2.887 & $4.905 .613,13$ & 2.465 \\
\hline 2005 & 85 & 189 & 4.271 & 4.348 & $7.820 .211,26$ & 2.286 \\
\hline 2006 & 109 & 209 & 3.454 & 3.417 & $6.299 .650,53$ & 2.772 \\
\hline 2007 & 116 & 206 & 3.637 & 5.999 & $9.914 .276,59$ & 3.139 \\
\hline 2008 & 158 & 301 & 3.021 & 5.016 & $9.011 .762,84$ & 4.892 \\
\hline 2009 & 156 & 350 & 3.412 & 3.769 & $5.908 .897,07$ & 4.535 \\
\hline 2010 & 0 & 0 & 2.745 & 0 & 0,00 & 0 \\
\hline Total & 1.082 & 2.845 & 36.419 & 39.180 & $62.247 .947,36$ & 31.583 \\
\hline
\end{tabular}

Fonte: SIT/SRTE (2011).

* dados preliminares

Outra ação governamental foi o lançamento, em 2003, do Plano Nacional para a Erradicação do Trabalho Escravo (PNETE); como parte deste Plano, em agosto de 2003, foi criada a Comissão Nacional para a Erradicação do Trabalho Escravo (CONATRAE), órgão colegiado vinculado à Secretaria Especial dos Direitos Humanos da Presidência da República, com função primordial de monitorar a execução do PNETE, a tramitação de projetos de Lei no Congresso, avaliar os projetos de cooperação técnica com organismos internacionais, estimular a criação de COETRAEs, ou seja, Comissões Estaduais e propor estudos e pesquisas sobre o trabalho escravo. Atualmente, há oito COETRAEs, ligadas aos estados de: Bahia, Maranhão, Mato Grosso, Mato Grosso do Sul, Pará, Rio de Janeiro, Tocantins e São Paulo em diversos estágios de consolidação.

Pela Portaria no. 540, de 15 de outubro de 2004, foi estabelecido como instrumento para auxiliar no combate ao trabalho escravo, pelo Ministério do Trabalho e Emprego (MTE), o Cadastro de Empregadores Infratores, conhecido como "Lista Suja". Este instrumento se mostra bastante positivo enquanto mecanismo de repressão e denúncia, já que a lista é de livre acesso pela internet. No entanto, mostra-se insuficiente, uma vez que, mantém o nome do empregador flagrado somente por dois anos, depois deste prazo, apenas mediante novo flagrante o empregador voltará à lista, mesmo que ainda que não tenha sido finalizado o processo. 
Como medida auxiliar, há também, a recomendação do Ministério da Integração Nacional para que sejam coibidos financiamentos dos Bancos Federais a estes empregadores.

O Ministério do Desenvolvimento Agrário (MDA) e o Instituto Nacional de Colonização e Reforma Agrária (INCRA), tem tentado utilizar a "Lista Suja" para a arrecadação de terras em situação irregular para projetos de reforma agrária, regulamentado pela Portaria $n^{\circ}$. 835/04, em imóveis rurais autuados por trabalho escravo. No entanto, muito pouco tem se avançado neste sentido. De acordo com MTE (2009), em 2005, as primeiras análises identificaram que apenas 16 dos 52 imóveis constantes da primeira Lista Suja do MTE e 21 dos 49 da segunda, atendiam às determinações legais da propriedade, sendo um indício de posse e uso irregular de terras.

Outra forma de ação deste órgão é a desapropriação de imóveis por descumprimento da "função social trabalhista". Segundo Oliveira et al. (2010), o Supremo Tribunal Federal julga atualmente recurso dos proprietários da fazenda Cabaceiras, com área de quase 10 mil ha, situada em Marabá, no sudeste do Pará, zona de intensos conflitos fundiários que, em outubro de 2004, foi desapropriada por exploração de trabalho escravo.

A própria Constituição Brasileira, no artigo 170 que trata dos Princípios Gerais da Atividade Econômica diz que

Art 170. A ordem econômica, fundada na valorização do trabalho e na livre iniciativa, tem por fim assegurar a todos existência digna, conforme os ditames da justiça social, observados os seguintes princípios: I - soberania nacional; II - propriedade privada; III - função social da propriedade; IV - livre concorrência; V - defesa do consumidor; VI - defesa do meio ambiente; VII - redução das desigualdades regionais e sociais; VIII - busca do pleno emprego; IX - tratamento favorecido para empresas de pequeno porte constituídas sob as leis brasileiras e que tenham sede e administração no País. (grifo nosso). (BRASIL, 1988)

Segundo Oliveira et al. (2010), os entraves quanto à erradicação do trabalho escravo são inúmeros. Apesar do direito penal definir este ato como criminoso, o que vem prevalecendo é a impunidade. Quando as condenações criminais ocorrem, na maioria das vezes, são transformadas em Termos de Ajustamento de Conduta (TACs), que é um meio alternativo para soluções extrajudiciais de conflitos.

A sanção penal tem sido insuficiente. Menos de $10 \%$ dos envolvidos em trabalho escravo no sul-sudeste do Pará, entre 1996 e 2003, foram denunciados por esse crime, de acordo com a Comissão Pastoral da Terra. A questão da competência para julgar o crime e o tamanho atual da pena mínima prevista no artigo 149 do Código Penal (dois anos) tem inibido qualquer ação penal efetiva (...). Se julgado, há vários dispositivos que permitem abrandar a eventual execução da pena. Ela pode ser convertida em distribuição de cestas básicas ou prestação de serviços à comunidade, por exemplo. Há medidas que vêm sendo tomadas na tentativa de atingirem economicamente quem se vale desse tipo de mão-deobra como as ações movidas pelo Ministério Público do Trabalho. Ações Civis por danos morais tem sido aceitas por juízes do Trabalho com valores cada vez mais elevados (REPORTER BRASIL, 2010).

A expropriação do trabalho humano também não tem fronteiras, mas tem destino. No Brasil, de acordo com os dados do MTE (2009), 40\% deste destino têm sido para as fazendas de pecuária, em atividades como limpeza e preparo do pasto. As lavouras temporárias, principalmente, relacionadas ao cultivo da cana-de-açúcar, cereais, algodão herbáceo, fumo e soja, apresentaram $17 \%$ do total dos estabelecimentos com trabalhadores resgatados. Enquanto que a categoria produção florestal foi a terceira com aproximadamente $11 \%$ do total de trabalhadores resgatados.

O recente trabalho "Atlas do Trabalho Escravo no Brasil", realizado por Thery et al (2009), faz um mapeamento do trabalho escravo no Brasil. Dele extraímos o cartograma exposto na Figura 1, onde se podem observar os locais de resgates dos trabalhadores em condições análogas a escravo 
Embora distribuídos em quase todo o país, estão concentrados fortemente no Pará, Maranhão e Tocantins, apresentando-se como um contínuo espacial de resgates.

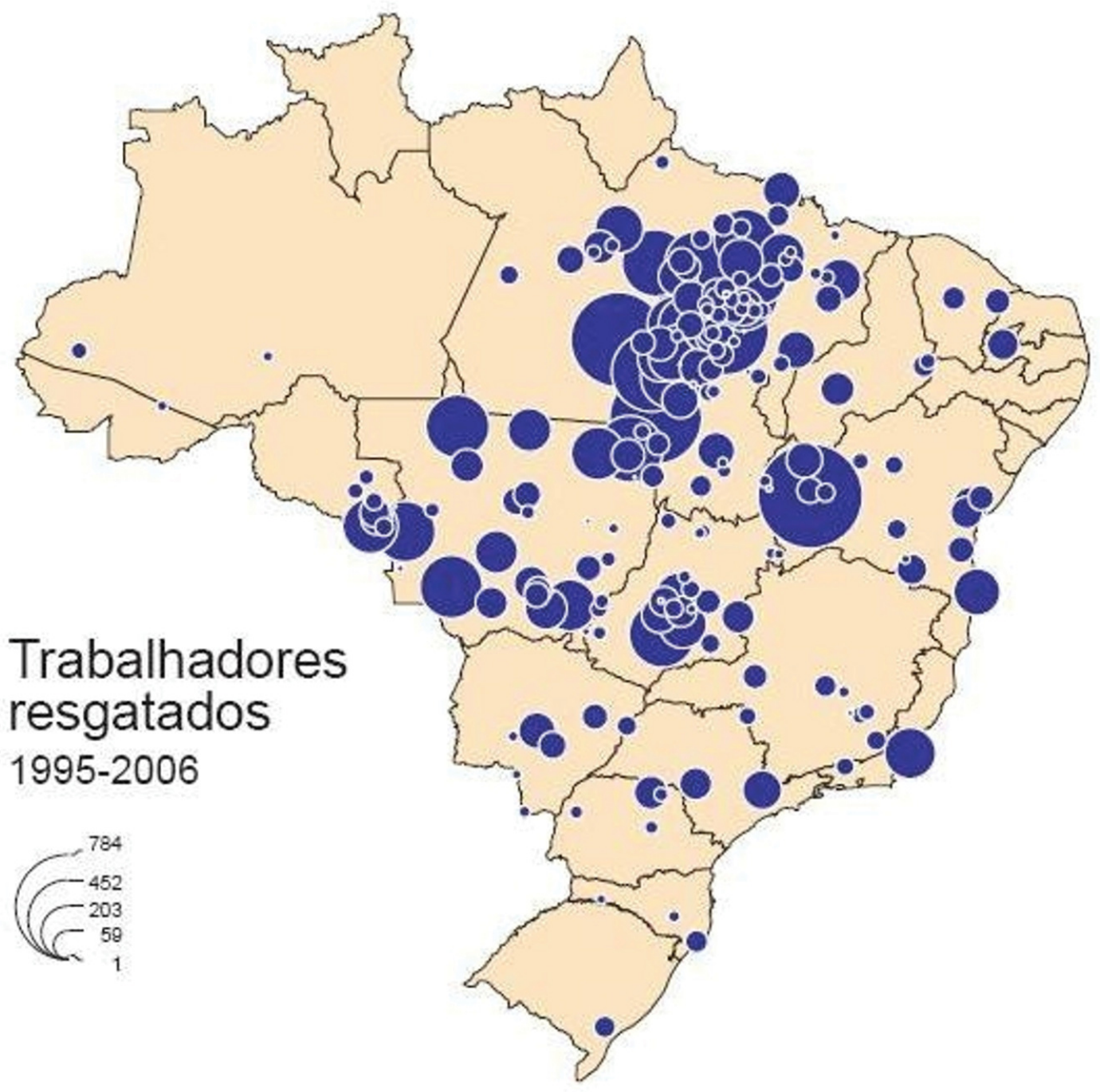

Figura 1 - Locais de resgate de trabalhadores em condições análogas a escravo, 1995-2006. Brasil Fonte: THERY et al, 2009, p. 22

No Mato Grosso encontra-se disperso em todo o estado; na Bahia, principalmente, em sua porção Oeste, adentrando no estado de Goiás e no Piauí. Este espaço compõe-se de uma área de especulação de comercialização de terras denominado por alguns de MAPITOBA (Maranhão, Piauí, Tocantins e Bahia), situado no cerrado brasileiro, cuja condição estratégica se revela pelos baixos preços da terra e facilidades na logística de escoamento dos produtos. Esta espacialização tem forte relação com áreas nas quais a produção agropecuária vem se expandido com maior acumulação de capital.

De acordo com informações da Comissão Pastoral da Terra (CPT) e as contidas na Lista Suja do Trabalho Escravo, tem-se que houve pequeno recrudescimento das denúncias, entre 2003 e 2010, conforme apresentado no Quadro 3. Verifica-se que os mesmos estados se repetem ao longo do período considerado, principalmente, Pará, Mato Grosso e Maranhão. Tem-se como novo estado, dentre os líderes de denúncias, o estado de Goiás. 
Quadro 3 Comparativo quanto às denúncias, trabalhadores envolvidos e proprietários infratores, principais estados, 2003 a 2010

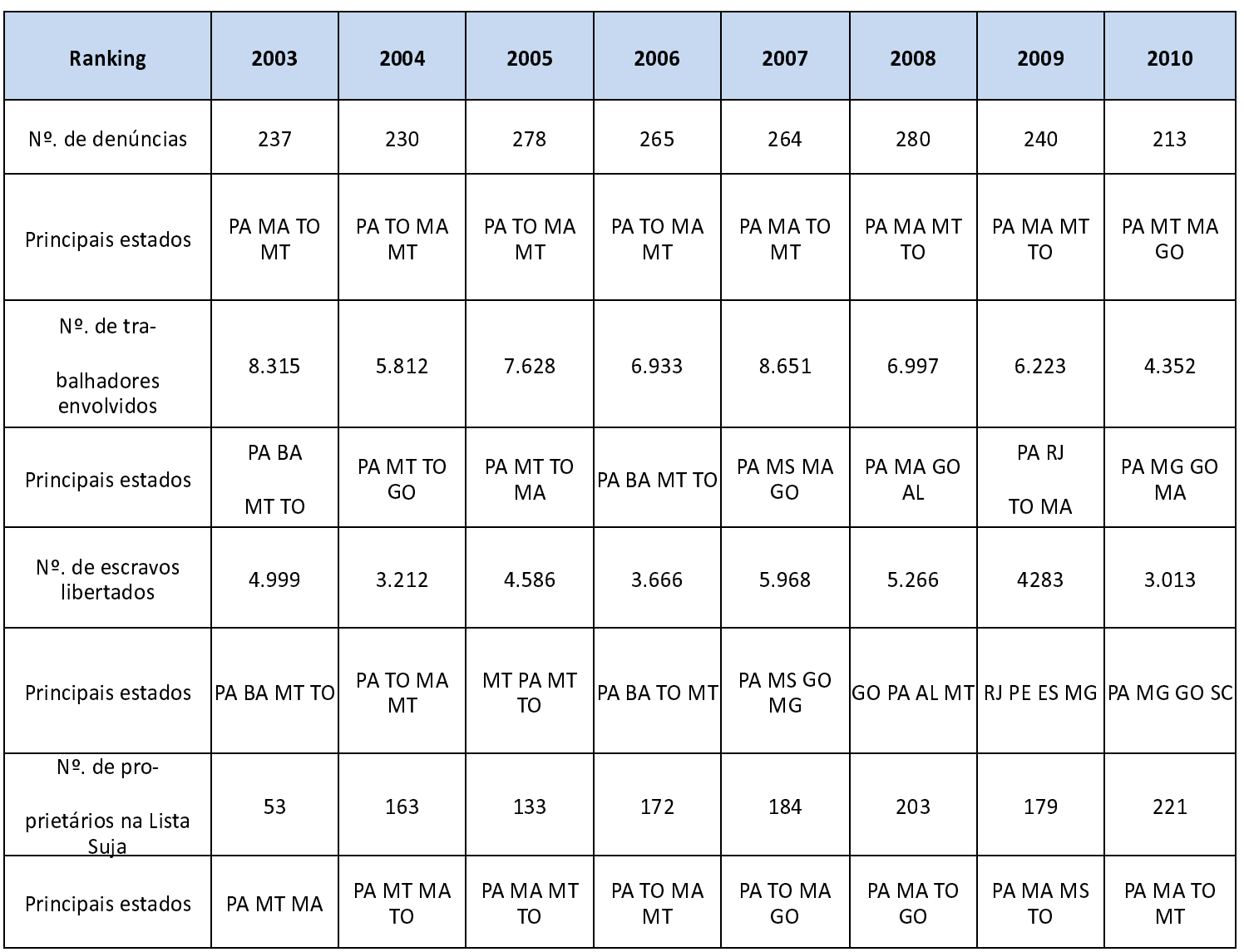

Fonte: Comissão Pastoral da Terra (CPT, 2009), Lista suja do trabalho escravo.

* 2010 - dados preliminares

Quanto ao número de trabalhadores resgatados da condição de trabalho análogo a escravo, tem-se redução significativa, apesar dos dados de 2010 ainda serem preliminares. Pará e Mato Grosso são os estados de maior destaque e que se repetem com maior frequência ao longo do período considerado. Observa-se que, no ano de 2010, o estado de Santa Catarina surge dentre as lideranças. No entanto, o número de proprietários adicionados no cadastro de empregadores infratores, comumente conhecida como Lista Suja, cresceu consideravelmente, passando de 53 para 221 infratores, a maioria deles no Pará, Maranhão e Mato Grosso.

Com as informações levantadas quando do resgate dos trabalhadores no qual são calculadas as indenizações é possível estabelecer o local de origem dos trabalhadores resgatados. Estas informações apontam a espacialização dos locais de residência dos trabalhadores resgatados, apresentada na Figura 2, também do Atlas do Trabalho Escravo no Brasil (THERY et al, 2009, p. 22).

Fica evidenciado que a maior concentração destes trabalhadores está no cinturão Pará, Maranhão, Tocantins e o oeste do Piauí. Mas, é possível identificar pontos espalhados em praticamente todo o território nacional refletindo a sujeição do trabalho ao capital na sua mais dramática expressão, o trabalho análogo a escravo. É interessante observar a coincidência de algumas áreas de concentração de trabalhadores resgatados e de sua origem. Porém, somente o aprofundamento destas informações levaria a uma compreensão melhor da mobilidade da força de trabalho relacionando os dados dos locais de origem e de resgate.

De acordo com Oliveira et al. (2010), além das ações de resgate, penalidade e outras punições há que se atuar nas causas que levam as pessoas a se submeterem a trabalhos degradantes, em con- 
dições análogas ao trabalho escravo e sem a garantia dos direitos trabalhistas. Uma das causas que impulsionam as pessoas à migração e, em especial, o tipo de migração que impõe a situação análoga ao trabalho escravo, é o fato de não encontrarem nos lugares de origem condições de trabalho e de reprodução social da vida. No campo, isso pode ser verificado pela excessiva concentração fundiária presente em todo o território nacional.

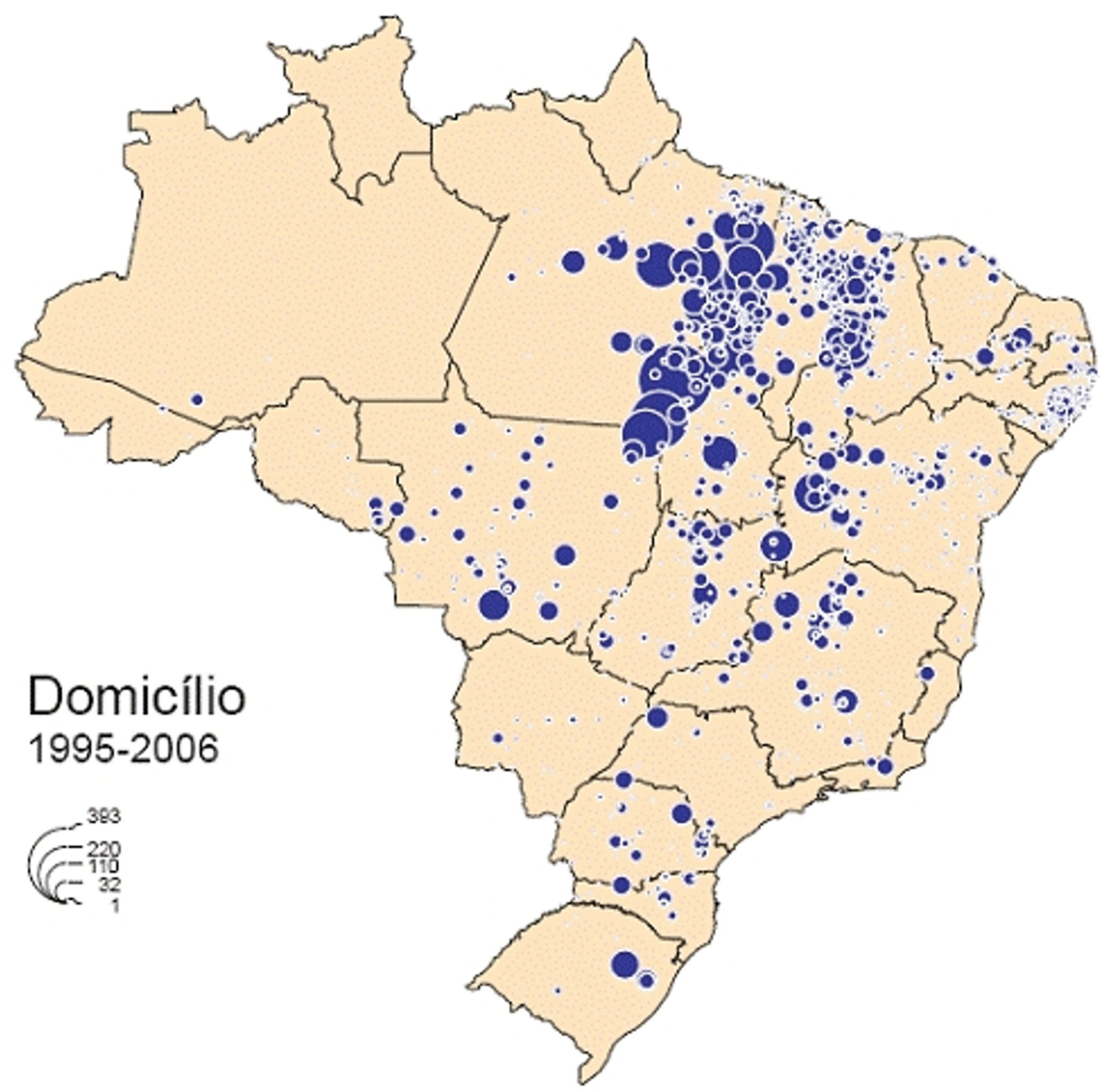

Figura 2 - Locais de residência de trabalhadores resgatados em condições análogas a escravo, 1995-2006. Brasil Fonte: THERY et al, 2009, p. 22

No Brasil, tomando como base os dados do Censo Agropecuário de 1996/97, tem-se que $49,66 \%$ dos estabelecimentos estão concentrados no grupo de área com menos de 10 ha e detém apenas $2,23 \%$ da área. No outro extremo, tem-se o correspondente a $1,0 \%$ dos estabelecimentos, que detém 45,10\% da área distribuídas nos grupos de áreas com mais de 1.000 ha. Mesmo considerando as limitações apresentadas nas informações divulgadas pelo Censo de 2006, tem-se, para o Brasil, uma pequena diminuição nos dois grupos de área que não altera uma situação de altíssima concentração de terras. Tem-se que $47,87 \%$ dos estabelecimentos estão concentrados no grupo de área com menos de 10 ha e detém $2,37 \%$ da área. No outro extremo, tem-se que o correspondente a $0,91 \%$ dos estabelecimentos, que detém $44,42 \%$ da área distribuídas nos grupos de áreas com mais de 1.000 ha (IBGE, 1995/96 e 2006).

No entanto, há que se observar para além dos números referentes à estrutura fundiária conforme relata José de Souza Martins 
A propriedade fundiária não se concentra nem se divide sem a mediação do capital. [...] a terra não é, no capitalismo, unicamente um instrumento de produção. Se me limito a ver na chamada estrutura fundiária, na distribuição da terra em propriedades grandes, médias e pequenas, apenas quantidades, mais concentração fundiária, menos concentração, estou vendo o supérfluo, não estou vendo o essencial. Não estou vendo que por trás de diferentes tamanhos de propriedade, de diferentes quantidades, existem situações e relações de qualidades diferentes. A propriedade da terra no capitalismo não é, como parece, apenas um dado, um número, um tamanho. A propriedade da terra é uma relação social (MARTINS, 1980, p. 42).

A relação social descrita por José de Souza Martins é sem a dúvida a sujeição do trabalhador ao capital que o expõe a condições degradantes, no processo de "acumulação primitiva", na qual o trabalhador se desvincula da propriedade por não ter condições de retirar dali a reprodução social, sendo levado a se deslocar para o trabalho forçado, garantindo a apropriação de seu trabalho pelo capital. Assim como ocorre a acumulação ampliada do capital, uma vez que, com a formação do mercado de trabalho assalariado e do capital, este se assenhora da mais-valia daquele se reproduzindo às suas custas.

Conforme trata Furtado (1980), o desenvolvimento de um país subdesenvolvido necessita de mudanças estruturantes e dentre elas estaria a reforma agrária como forma de romper com a acumulação do capital que garante estratificação social com a manutenção da estrutura de dominação vigente que continuaria mantendo as desigualdades na repartição do produto social. Na realidade, a espacialização dos dados revela que nas áreas de expansão e consolidação das fronteiras agrícolas nacionais, há um processo de dinamização da economia agroexportadora, amplamente apoiado pelas políticas governamentais que reestruturam as economias locais, fortalecendo as estruturas de dominação e aumentando as desigualdades socioespaciais.

Com vistas a efetivar estas mudanças estruturais seria necessário cumprir o que gere a Constituição Federal. Mas há forças econômicas e políticas que impedem seu cumprimento. A recente aprovação da PEC 438/2001 - que permite a expropriação de imóveis rurais e urbanos onde a fiscalização trabalhista encontrar exploração de Trabalho Escravo degradante, e os destinará à Reforma Agrária e a programa habitacional popular - foi uma bandeira da luta contra o trabalho escravo por inserir na função social da terra a não incidência de trabalho análogo a escravo. No entanto, apesar de sua importância, por garantir a dignidade do ser humano, sua aprovação vinha sendo protelada, principalmente por interesses defendidos pela Bancada Ruralista. Em 22 de maio de 2012, esta PEC é aprovada por $87 \%$ dos presentes (360/415) contra 7\% contrários (29/415) e 6\% de abstenções (25/415). No entanto, ainda se tem que buscar a aprovação em segunda instância no Senado.

Importante ressaltar que, dentre os fatores que impelem trabalhadores para este tipo de trabalho forçado, tem-se a carência de oportunidades de trabalho decente e a falta de acesso à terra com condições de garantir sua reprodução social.

\section{CONSIDERAÇÕES FINAIS}

Após as diversas denúncias em instituições internacionais ligadas à Organização das Nações Unidas, somadas com as das redes sociais mundiais, o governo brasileiro assume que no País havia trabalhadores sujeitos a condições degradantes de trabalho. $\mathrm{O}$ reconhecimento põe em movimento diversas instâncias do estado brasileiro e da sociedade civil, na tentativa de se coibir essa degradante relação de trabalho que mancha o status de nação democrática. As iniciativas dos vários governos começaram a surtir efeito internamente e mundialmente porque as ações empreendidas, progressivamente vão apresentando resultados positivos.

No entanto, muitas das propostas não se efetivaram e as ações têm sido demasiadamente lentas e o que se observa é a permanência desta exploração inaceitável do trabalhador. 
Medidas contundentes de combate têm que ser tomadas como aumento de seu orçamento e designação de maior contingente para atuar no Grupo Especial de Fiscalização Móvel (GEFM), como ação prioritária de combate. Há que se identificar nas cadeias produtivas a presença de elos onde se dá a sujeição de trabalhadores ao trabalho análogo a escravo para que sejam denunciados junto à sociedade e punidos. A Lista Suja precisa servir como forma, também, de conscientização da população para que possa agir na ponta do consumo, influenciando um processo produtivo decente. Assim como medidas punitivas de não acesso a financiamento público e a outros benefícios advindos de recursos públicos devem ser amplamente efetivados.

Ações estruturantes também precisam ser realizadas como a aprovação da PEC 438 que expropria as áreas onde se tem trabalho escravo para fins de reforma agrária. Esta proposta de emenda constitucional encontrou resistência em seu debate pelas constantes denúncias de envolvimento de políticos nesta prática.

Não basta resgatar. É preciso romper com as condições de vulnerabilidade que alimentam o círculo vicioso e criar condições para que estes trabalhadores possam ser reinseridos, de forma digna, na sociedade e tenham garantida a sua reprodução social.

A sujeição de trabalhadores a condições análogas à de escravo, degradantes, expropriadoras de direitos humanos, sem garantia dos direitos civis, geram extrema indignação coletiva que necessita ser transformada em ação política. Portanto, a sociedade precisa se mobilizar e cobrar ação do Estado contra tal ato com o intuito de garantir a dignidade humana, conforme estabelecido no pensamento seminal da Constituição Federal desta nação.

\section{AGRADECIMENTOS}

Este artigo faz parte dos estudos preliminares da Pesquisa "Diagnóstico e Mapeamento do Trabalho Escravo no Estado da Bahia" conduzido pelo Grupo de Pesquisa GeografAR/UFBA em parceria com a Comissão Pastoral da Terra (CPT/BA) e Associação dos Advogados dos Trabalhadores Rurais (AATR) e com apoio do CNPq. Participa também deste estudo como bolsista PIBIC/ CNPq o estudante Hernane Nery.

\section{REFERÊNCIA BIBLIOGRÁFICA}

BRASIL. Presidência da República. Casa Civil. Subchefia para Assuntos Jurídicos. Constituição da República Federativa do Brasil de 1988. Disponível em: http://www.planalto.gov.br/ccivil_03/constituicao/ constitui\%C3\%A7ao.htm. Acesso em 10/02/2009.

BRASIL. Presidência da República. Casa Civil. Subchefia de Assuntos Jurídicos. Lei no 10.608 de 20 de dezembro de 2002. Disponível em: http://www.planalto.gov.br/ccivil_03/leis/2002/L10608.htm. Acesso em 31/06/2009.

BRASIL. Presidência da República. Casa Civil. Subchefia de Assuntos Jurídicos. Lei no 10.803 de 11 de dezembro de 2003. Disponível em: http://www.planalto.gov.br/ccivil_03/Leis/2003/L10.803.htm. Acesso em 31/06/2009.

BRASIL. MINISTÉRIO DO TRABALHO E EMPREGO. SECRETARIA DE INSPEÇÃO DO TRABALHO. Ações do MTE no enfrentamento ao Trabalho Escravo. Brasília, 18 de dezembro de 2009. 11 p. CARVALHO, J. M. Cidadania no Brasil: O longo caminho. Rio de Janeiro: Civilização Brasileira, 2011. $236 \mathrm{p}$.

CEPAL, PNUD, OIT. Emprego, desenvolvimento humano e trabalho decente: a experiência brasileira recente. Brasília. 2008.

COMISSÃO PASTORAL DA TERRA(CPT). Campanha da CPT contra o Trabalho Escravo. Estatística em 31/12/2009.

FURTADO, Celso. Pequena Introdução ao Desenvolvimento: Enfoque Interdisciplinar. São Paulo: Ed. Nacional, 1980. 161 p. 
IBGE. Censo Agropecuário, 1995/1996 e 2006.

IBGE. Instituto Brasileiro de Geografia e Estatística. Censo Agropecuário. Conceitos. Disponível em: http://www.ibge.gov.br/home/estatistica/economia/agropecuaria/ censoagro/ conceitos.shtm. Acesso em: 10/02/2009.

MARTINS, José de Souza. A sujeição da renda da terra ao capital e o novo sentido da luta pela Reforma Agrária. Boletim de Geografia Teorética. Rio Claro, 10 (19), 1980, p. 31-47.

MIRAGLIA, L. M. M. Trabalho escravo contemporâneo: conceituação à luz do princípio da dignidade da pessoa humana. São Paulo: LTr, 2011. 200 p.

OLIVEIRA, G. G; GUIOMAR, I. G.; BORBA, L. S. B. Trabalho escravo na Bahia. Superintendência de estudos econômicos e sociais da Bahia. Bahia: Revista Bahia Análise de dados: Trabalho decente. P. 255.274. 2010. Disponível em: http://www.sei.ba.gov.br/index.php?option $=$ com_content\&view $=$ article\&id $=80 \&$ Itemid=110. Acesso em 07/09/2011.

REPÓRTER BRASIL. Lista suja do trabalho escravo. Disponível em: www.reporterbrasil.org.br/listasuja. REPÓRTER BRASIL. Disponível em: http://www.reporterbrasil.org.br/. Acesso em: 03/09/2010.

SIT/SRTE. MINISTÉRIO DO TRABALHO E EMPREGO. SECRETARIA DE INSPEÇÃO DO TRABALHO. Quadro das Operações de Fiscalização Para Erradicação Do Trabalho Escravo. 1995 a 2010.

THERY, H.; MELLO, N. A. de; HATO, J.; GIRARDI, E. P. Atlas do Trabalho Escravo. São Paulo:Amigos da Terra. 2009. Disponível em: http://amazonia.org.br/wp-content/uploads/2012/04/Atlas-do-Trabalho-Escravo.pdf 